\title{
Review: oral or parenteral opioids alleviate dyspnoea in palliative care
}

\author{
Jennings AL, Davies AN, Higgins JP, et al. A systematic review of the use of opioids in the management of dyspnoea. \\ Thorax 2002;57:939-44.
}

\section{QUESTION: Are opioids effective in the treatment of dyspnoea?}

\section{Data sources}

Studies were identified by searching Medline (19661999), EMBASE/Excerpta Medica (1980-1999), CANCERLIT (1988-1999), CINAHL (1982-1999), the Cochrane Library, Dissertation Abstracts, and SIGLE; reviewing the reference lists of relevant studies, reviews, and book chapters; and contacting authors, other experts in the field, and palliative care organisations.

\section{Study selection}

Studies were selected if they were randomised, double blind, placebo controlled trials of any opioid to alleviate breathlessness in patients with dyspnoea.

\section{Data extraction}

Data were extracted by 2 independent reviewers on study quality (concealment, blinding, withdrawals, and dropouts), disease that causes dyspnoea, intervention (opioid used and dosage), study methods, and results. The main outcome measure was a subjective assessment of dyspnoea. In studies of patients at rest, the breathlessness measurement nearest to 1 hour after opioid administration was used; in studies with exercise tests, the breathlessness measurement relating to the exercise test was used. Dyspnoea measurements recorded at a fixed point during exercise or after a fixed length of exercise were used for meta-analysis.

\section{Main results}

18 crossover trials met the inclusion criteria. 9 trials involved oral ( 8 trials) or parenteral ( 1 trial) opioids (116 patients) and 9 involved nebulised opioids (177 patients). 9 trials of oral or parenteral opioids and 3 trials of nebulised opioids were included in a meta-analysis. Overall, opioids had a positive effect on the sensation of breathlessness (table). When trials of oral or parenteral opioids and nebulised opioids were analysed separately, only oral or parenteral opioids showed a positive effect (table).

Oral, parenteral, or nebulised opioids v placebo for dyspnoea*

\begin{tabular}{lll} 
Trials in meta-analysis & $\begin{array}{l}\text { Number } \\
\text { of trials }\end{array}$ & $\begin{array}{l}\text { Standardised mean } \\
\text { difference }(95 \% \mathrm{Cl})\end{array}$ \\
All trials & 12 & $-0.31(-0.50$ to -0.13$)$ \\
\hline Oral or parenteral opioids & 9 & $-0.40(-0.63$ to -0.17$)$ \\
\hline Nebulised opioids & 3 & $-0.11(-0.32$ to 0.10$) \dagger$
\end{tabular}

*All trials were crossover trials. Follow up not reported. $\mathrm{Cl}$ defined in glossary. A random effects model was used.

†Not significant.

\section{Conclusions}

Oral and parenteral opioids are effective in the treatment of dyspnoea. No beneficial effect is seen with nebulised opioids.

\section{COMMENTARY}

Opioids are commonly used to relieve dyspnoea in palliative medicine but their effectiveness is unclear. Jennings $e t$ al did a systematic review that included a meta-analysis of the effectiveness of opioids in relieving dyspnoea. Meta-analysis is necessary because of the small number of studies (only 18 were identified) and the small number of patients in each study (only 1 study had $>20$ patients).

Overall, opioids showed a beneficial effect in relieving the sensation of breathlessness, but when the type of opioid was examined, only parental and oral opioids reduced breathlessness. Opioid receptors are abundant in the lung, and it has been suggested that nebulised opioids might relieve dyspnoea or cough with minimal systemic effects. ${ }^{1}$ In this review, the nebulised opioids were ineffective compared with placebo in relieving the sensation of breathlessness. However, only 3 studies with 94 patients were combined in this analysis. It should be noted that the other 6 studies of nebulised opioids showed similar results but could not be included in the meta-analysis because of methodological or data insufficiencies.

Opioids were as effective in patients with chronic obstructive pulmonary disease (COPD) as in patients with cancer. Physicians have been reluctant to use opioids, especially in COPD, for fear of respiratory depression. However, 4 studies included in this review measured arterial blood gas tensions and reported no important changes during treatment. 9 studies that measured oxygen saturation also reported no important changes during treatment.

This review supports the use of oral and parenteral opioids to treat dyspnoea in palliative care, but does not support the use of nebulised opioids. Furthermore, the review suggests that fear of respiratory depression may be exaggerated based on the data reported in the review. Nevertheless, the authors conclude that more studies are needed, which seems reasonable given the small numbers of studies and patients.

Richard A Robbins, MD Arizona Respiratory Center Tucson, Arizona, USA

1 Zebraski SE, Kochenash SM, Raffa RB. Lung opioid receptors: pharmacology and possible target for nebulized morphine in dyspnea. Life Sci 2000;66:2221-31.
Sources of funding: Palliative Care Research Fund of the Royal Marsden Hospital and Sackler Foundation.

For correspondence: Dr A L Jennings, North London Hospice and Barnet and Chase Farm Hospitals, London, UK. ajennings@ northlondonhospice.co.uk

Abstract and commentary also appear in ACP Journal Club. A modified version of this abstract also appears in Evidence-Based Nursing. 